\title{
МОНИТОРИНГОВЫЕ НАБЛЮДЕНИЯ НА ГРАВИМЕТРИЧЕСКОМ ПОЛИГОНЕ В Г. БЕРЕЗНИКИ
}

\author{
А.А. Симанов \\ Горный институт УрО РАН, г. Пермь
}

\begin{abstract}
Аннотация. Представлены результаты пятилетних (2016-20 гг.) гравиметрических исследований на полигоне, организованном в г. Березники Пермского края. Полигон состоит из 102 пунктов, работы на котором выполняются гравиметрами AUTOGRAV CG-5. В каждом цикле измерений определяются не только значения силы тяжести, но и фиксируются изменения высот пунктов. По результатам гравиметрических наблюдений сделаны выводы о состоянии породного массива над затопленными шахтными полями, наличии разуплотненных зон и прослежено их изменения во времени и в пространстве. Разработанная технология проведения, обработки и интерпретации динамических аномалий силы тяжести позволяет повысить безопасность эксплуатации Верхнекамского месторождения.
\end{abstract}

Ключевые слова: гравиразведка, мониторинг, безопасность горных работ.

В 2016 г. над затопленными шахтными полями на территории г. Березники был создан гравиметрический полигон (рис. 1), состоящий из 102 пунктов, работы на котором выполняются на закрепленных металлических знаках (дюбелях, забитых в асфальт) гравиметрами AUTOGRAV CG-5. В каждом цикле измерений определяются не только значения силы тяжести, но и фиксируются изменения высот пунктов. Планововысотная привязка гравиметрических пунктов осуществляется с использованием GNSS-приемника Trimble R-8 [3, 4, 5, 6].

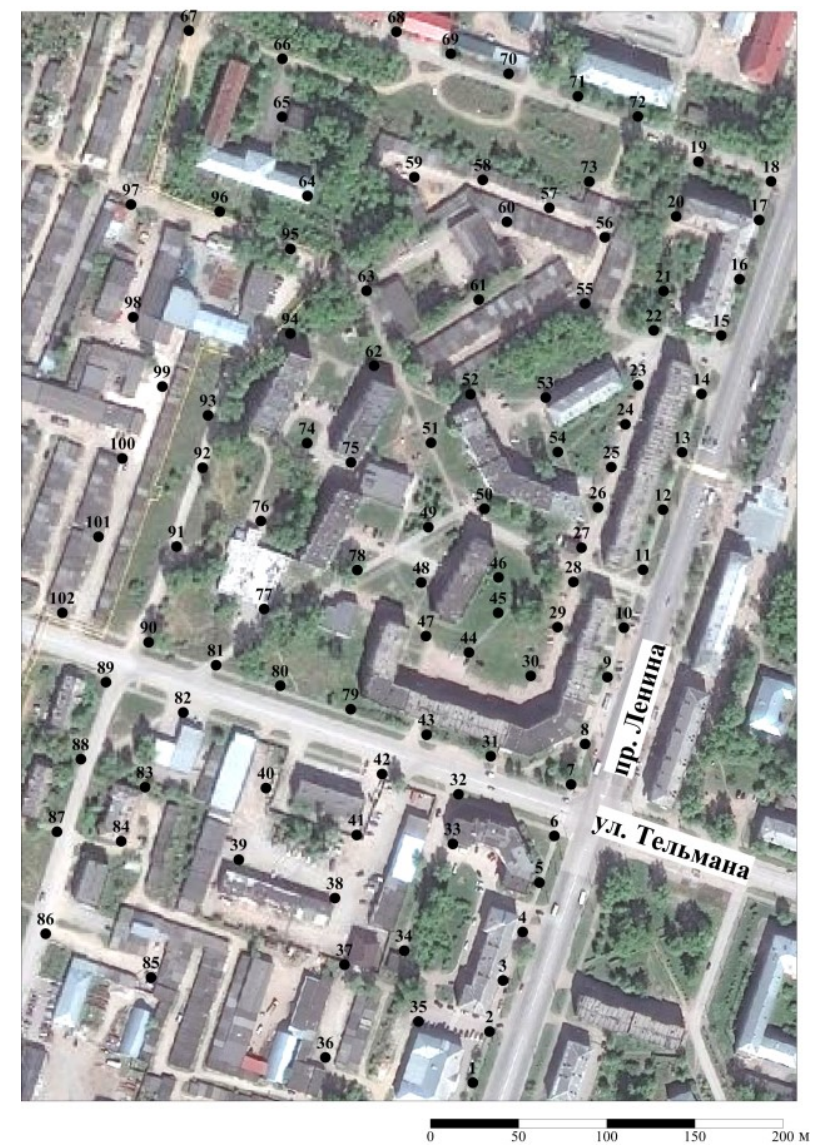

Рис. 1. Расположение гравиметрического полигона на карте г. Березники (черными точками показаны пункты гравиметрических наблюдений) 
Во всех циклах наблюдений сравнивались между собой аномалии в редукции Буге, т.е. учитывалось изменение высоты гравиметрических пунктов. Результаты пятилетних гравиметрических наблюдений на полигоне представлены на рис. 2 и 3.
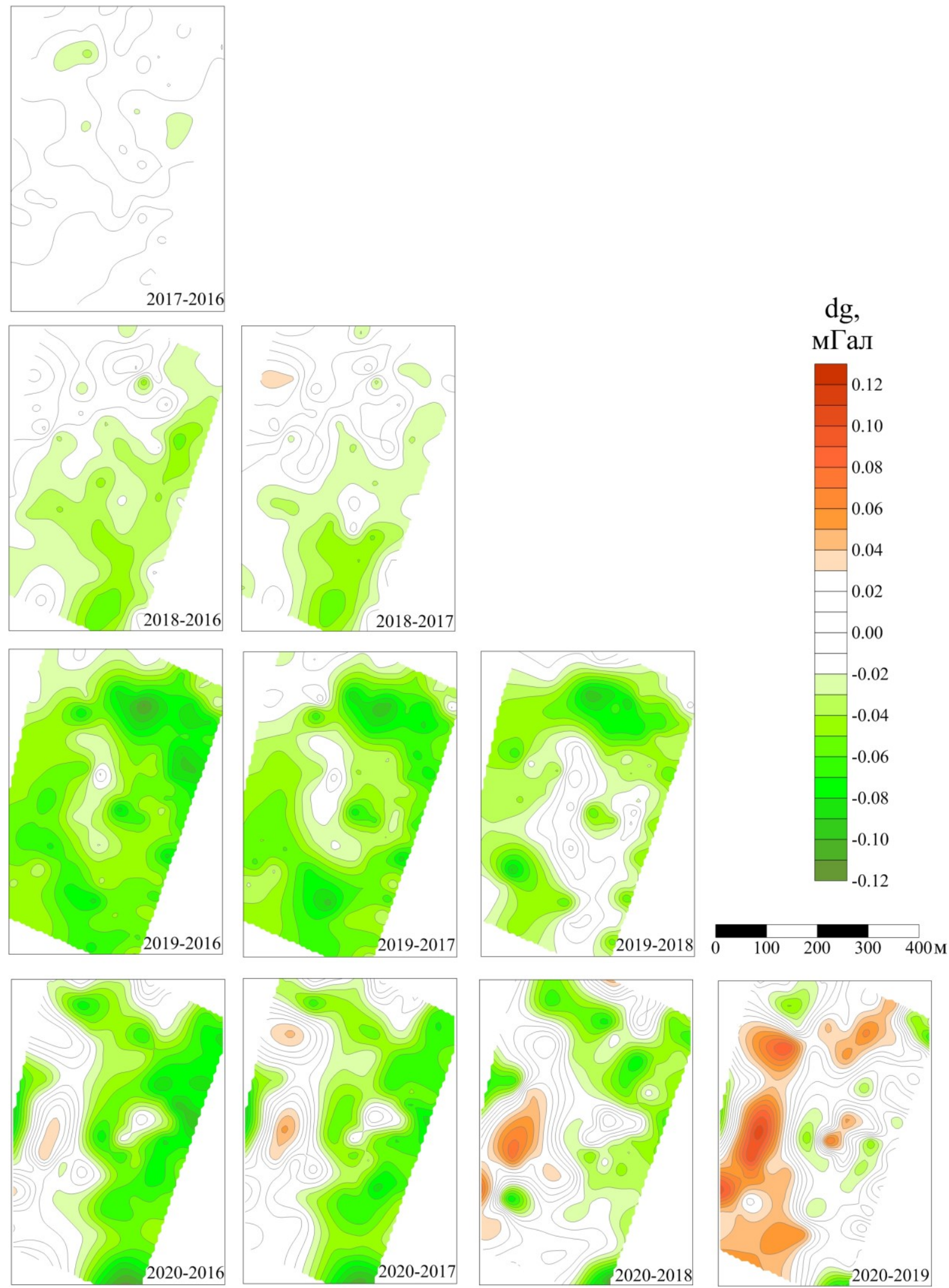

Рис. 2. Динамические аномалии силы тяжести, полученные в различные циклы наблюдений (цифрами на картах показан период в годах) 

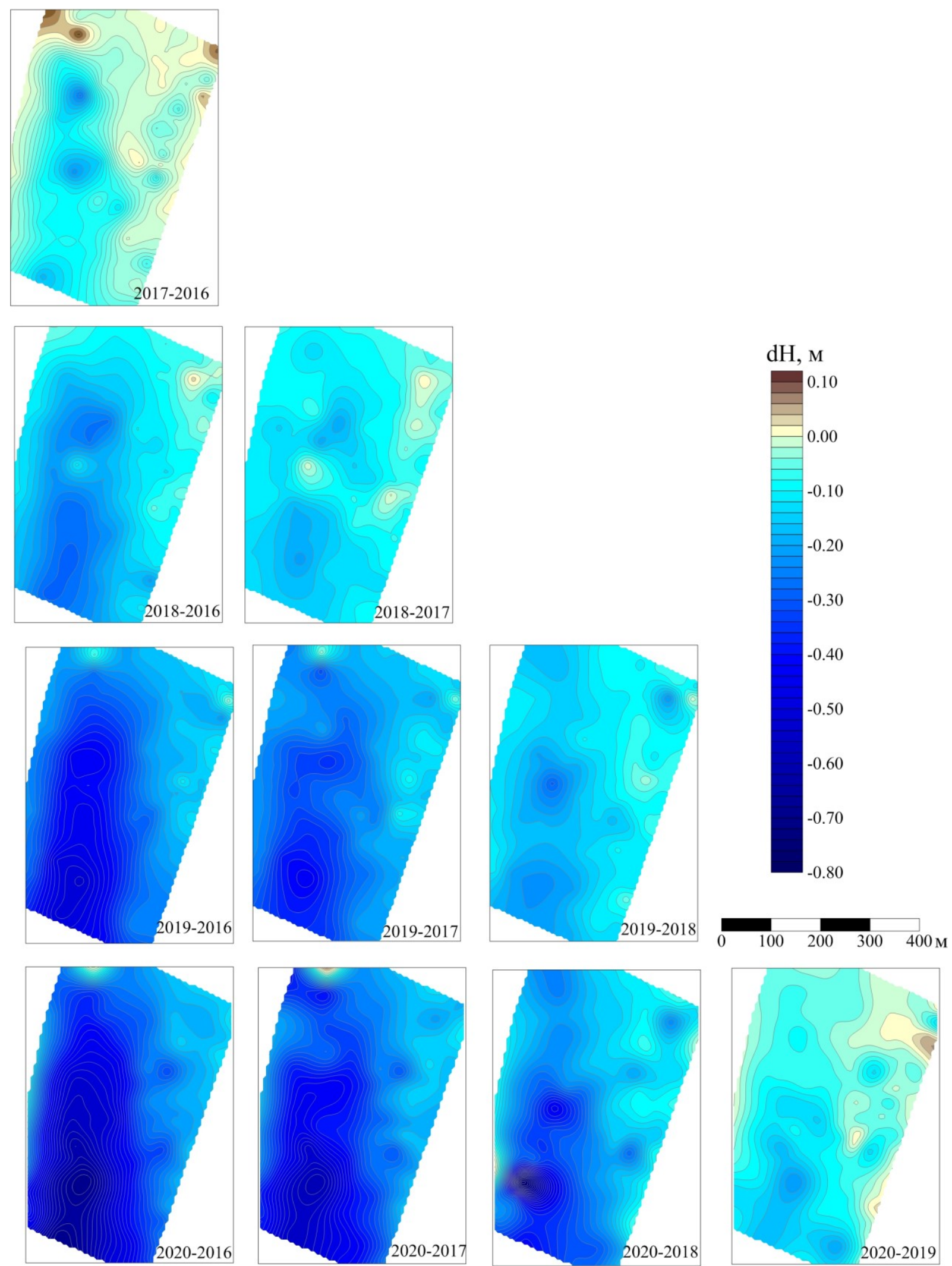

Рис. 3. Оседания земной поверхности, полученные в различные циклы наблюдений (цифрами на картах показан период в годах)

Анализируя карты динамических аномалий в разные периоды времени, прежде всего следует отметить, что амплитуда, размеры и местоположение динамических аномалий существенным образом меняются в различных циклах мониторинга. 
Можно констатировать увеличение скорости изменения силы тяжести: если в период 2016-17 гг. амплитуда отрицательной аномалий не составляла -0.05 мГал, то за 2018-19 гг. амплитуда увеличилась до -0.10 мГал. Количественная интерпретация динамических аномалий $[1,2,7]$ показала, что источник изменения поля находится на глубине порядка 20-40 м, плотность его изменилась на -0.1 г $^{\mathrm{cm}}{ }^{3}$. Увеличение амплитуды динамической аномалии свидетельствует об ускорении процесса разуплотнения пород надсоляной толщи, расположенной над затопленными шахтными полями, что в дальнейшем может привести к провалам земной поверхности на данной территории.

В 2020 г. интенсивность отрицательных динамических аномалий существенно уменьшилась. В период 2019-20 гг. произошло даже увеличение значений силы тяжести. Изменение формы и амплитуды динамических аномалий во времени и в пространстве, по нашему мнению, связано с процессом непрерывного оседания земной поверхности.

Участки повышенных оседаний сопровождаются уменьшением величины динамической аномалии, что объясняется компенсацией значений аномалий увеличением плотности пород, обусловленной оседанием. Например, в 2018 г. наиболее интенсивные динамические аномалии силы тяжести проявлялись на юге участка, в 2018-19 гг. здесь произошли повышенные оседания земной поверхности, что подтвердило сделанный нами ранее [4] прогноз оседаний. Одновременно с оседанием в этой части участка произошло «затухание» динамической аномалии. За период 2019-20 гг. произошла инверсия динамических аномалий, что свидетельствует о прекращении процесса разуплотнения пород или начале нового цикла «разуплотнение - оседание».

По результатам гравиметрических наблюдений можно делать выводы о состоянии породного массива над затопленными шахтными полями, наличии разуплотненных зон и прослежено их изменения во времени и в пространстве. Разработанная на полигоне технология проведения, обработки и интерпретации динамических аномалий силы тяжести позволяет повысить безопасность эксплуатации Верхнекамского месторождения.

Работа выполнена при поддержке РФФИ (проект № 19-45-590011p_а).

\section{БИБЛИОГРАФИЧЕСКИЙ СПИСОК}

1. Бычков С.Г., Мичурин А.В., Симанов А.А., Хохлова В.В. Выявление природных и техногенных разуплотненных зон в подработанной толще по гравиметрическим данным // Инженерная и рудная геофизика - 2020: 16-я науч.-практ. конф. и выставка, 14-18 сент. 2020. - Пермь, 2020. - DOI: 10.3997/2214-4609.202051031.

2. Бычков С.Г., Мичурин А.В., Симанов А.А., Хохлова В.В. Гравиметрические исследования состояния геосреды в районах интенсивного освоения недр // Горный журнал. - 2019. - № 12. - С. 90-94. DOI:10.17580/gzh.2019.12.19.

3. Симанов А.А. Мониторинговые гравиметрические наблюдения на потенциально опасных участках в г. Березники // Стратегия и процессы освоения георесурсов: сб. науч. тр. Вып. 15 / ГИ УрО РАН. Пермь, 2017. - С. 173-177.

4. Симанов А.А. Гравиметрический мониторинг карстово-суффозионных процессов в районах интенсивного освоения недр // Стратегия и процессы освоения георесурсов: сб. науч. тр. Вып. 16 / ГИ УрО PAH. - Пермь, 2018. - С. 161-163. DOI: 10.7242/gdsp.2018.16.42.

5. Симанов А.А. Методика совместного применения качественных и количественных методов решения обратных задач гравиметрии на примере результатов гравиметрического мониторинга // Горное эхо. - 2019. - № 4 (77). - C. 43-47. - DOI: 10.7242/echo.2019.4.10.

6. Симанов А.А. Разработка методики мониторинговых гравиметрических исследований для изучения карстовых процессов // Горное эхо. - 2020. - № 2 (79). - C. 62-66. - DOI: 10.7242/echo.2020.2.12. 
7. Bychkov S., Dolgal A., Simanov A. Interpretation of gravity monitoring data on geotechnical impact on the geological environment // Pure and applied geophysics. - 2021. - V. 178, № 1. - P. 107-121. - DOI: $10.1007 / \mathrm{s} 00024-020-02640-8$.

\title{
ПЛОТНОСТНОЕ СТРОЕНИЕ ВЕРХНЕЙ ЧАСТИ ГЕОЛОГИЧЕСКОГО РАЗРЕЗА НА ВОСТОКЕ ЛЕГЧИМСКОГО СТРУКТУРНОГО ВЫСТУПА
}

\author{
Г.П. Щербинина \\ Горный институт УрО РАН, г. Пермь
}

\begin{abstract}
Аннотация: Гравиметрический метод геофизики применяется на Верхнекамском месторождении калийных солей с 1986 года. Целью данного метода является выявление ослабленных разуплотненных участков в горном массиве, наличие которых необходимо учитывать при разработке месторождения для предотвращения аварийных ситуаций. На территории Легчимского выступа кровли соляной толщи, расположенного в восточной части Предуральского прогиба, была проведена гравиметрическая съемка, в результате которой на изучаемом участке выявлено около двух десятков разуплотненных зон. По приуроченности разуплотнений к разным эффективным (расчетным) глубинам проведена их классификация.

Ключевые слова: Верхнекамское месторождение калийных солей, гравиразведка, надсолевые отложения.
\end{abstract}

Одна из целей проведения гравиметрических работ на Верхнекамском месторождении - подготовка новых площадей к проведению работ по добыче полезного ископаемого $[1,2]$. Изученный гравиметрией участок расположен на северо-востоке территории Четвертого Березниковского калийного рудоуправления в восточной части Легчимского структурного выступа кровли соляной толщи (рис. 1). В 300-600 м севернее изучаемого участка находится южная граница Дуринской системы впадин.

Бурением участок практически не изучен, на момент проведения гравиметрических работ в пределах площади съемки была пробурена одна солеразведочная скв. № 1112 .

Особенностью данной территории является близкое к земной поверхности залегание кровли соляного массива - на глубине 170-220 м. Описание керна скв. 1112 и соседних с участком скважин говорит о выветрелом состоянии надсоляной толщи до дезинтеграции отдельных слоёв. О влиянии агентов выветривания на бо́льшей глубине, в зоне соляной толщи, свидетельствует пёстросильвинитовый состав карналлитовой зоны в скв. 524, расположенной недалеко от восточной границы участка (рис. 1). В скв. 552 (у северной границы площади исследований) отсутствуют покровная и продуктивная толщи и переходная пачка залегает на подстилающей соли.

Таким образом, геологические данные говорят о том, что на изучаемой площади надсоляная и соляная толщи должны иметь неоднородное плотностное строение, с участками выветрелых разуплотненных пород. В гравитационном поле такие участки будут отражаться локальными отрицательными аномалиями.

Подготовка территории к разработке проводилась с целью выявления разуплотненных зон в водозащитной толще, которые априори представляют участки с ослабленными механическими и прочностными свойствами. Для учета их влияния на состояние подработанного массива в процессе проведения горных работ была проведена детальная гравиметрическая съемка масштаба 1:10 000 с плотной сетью пунктов наблюдения $(50 \times 200$ м). Измерение поля силы тяжести осуществлялось современными высокоточ- 